\title{
Plasma uric acid level indicates tubular interstitial leisions at early stage of IgA nephropathy
}

Jingjing Zhou ${ }^{1,2,3,4}$, Yuqing Chen ${ }^{1,2,3,4^{*}}$, Ying Liu' ${ }^{1,2,3,4}$, Sufang Shi ${ }^{1,2,3,4}$, Xueying Li ${ }^{5}$, Suxia Wang ${ }^{6}$ and Hong Zhang ${ }^{1,2,3,4}$

\begin{abstract}
Background: Hyperuricemia appeared to be a common symptom in IgA nephropathy (IgAN), even in those with normal eGFR. IgAN was characterized by variation of pathological features, especially variable tubulointerstitial lesions. Since tubular reabsorption and excretion appeared to be more important in determination of plasma uric acid levels in persons without obvious decrease of glomerular filtration rate, we took advantage of our IgAN cohort to investigate whether plasma uric acid level associated with tubular interstitial lesions, and could be considered as a maker for tubular interstitial lesions, especially at early stage with normal eGFR.
\end{abstract}

Methods: 623 IgAN patients were involved in the present study. Morphological changes were evaluated with Oxford classification scoring system as well as Beijing classification system of IgAN. Statistical analysis was done with SPSS 13.0.

Results: We found that plasma uric acid level associated with percentage of interstitial fibrosis/tubular atrophy. Higher plasma uric acid levels indicated higher tubulointerstitial scores, either with Oxford system $(P=0.012)$ or with Beijing classification system $\left(P=4.8^{*} 10^{-4}\right)$ in the whole cohort. We also found that in the subgroup of $258 \lg A N$ cases with normal baseline eGFR (eGFR $>=90 \mathrm{ml} / \mathrm{min} / 1.73 \mathrm{M}^{2}$ ), higher plasma uric acid associated with more severe tubulointerstitial lesions with Beijing scoring system $\left(P=3.4^{*} 10^{-5}\right)$. The risk of having more than $10 \%$ tubulointerstitial lesions in patients with hyperuricemia increased 58\% compared with normal uric acid level. In subgroup with normal eGFR, only hyperuricemia predicted tubulointerstitial leisions, and the risk of having more tubulointerstitial changes increased 100\%. Among these patients, hyperuricemia was associated with more tubulointerstitial lesions with a specificity of $60.3 \%$. Specificity increased to $65 \%$ among those patients with eGFR $>=90 \mathrm{ml} / \mathrm{min} / 1.73 \mathrm{~m}^{2}$.

Conclusions: Plasma uric acid levels indicate tubular interstitial lesions in IgAN and hyperuricemia may be considered as a marker for tubulointerstitial lesions.

Keywords: IgA nephropathy, Plasma uric acid levels, Tubulointerstitial lesions

\section{Background}

Hyperuricemia appeares to be a common manifestation in IgA nephropathy (IgAN) patients, even when their glomerular filtration rate (GFR) are normal and hyperuricemia has been considered as a risk factor of chronic kidney disease progression [1-4]. However, why plasma uric acid level elevated in part of IgAN patients with young age and normal GFR did not get enough attention.

\footnotetext{
* Correspondence: cyq@bjmu.edu.cn

${ }^{1}$ Renal Division, Department of Medicine, Peking University First Hospital, Beijing 100034, China

${ }^{2}$ Institute of Nephrology, Peking University, Beijing 100034, China

Full list of author information is available at the end of the article
}

It is well known that renal handling of uric acid excretion is a major denominator of plasma uric acid levels in adults with hyperuricemia [5-7]. Renal uric acid excretion is regulated by multiple factors such as glomerular filtration rate, tubular re-absorption and excretion [5,7]. Tubular reabsorption and excretion appear to be more important in determination of plasma uric acid levels in persons without obvious decrease of GFR.

IgAN is characterized by variation of pathological features, especially variable tubulointerstitial lesions from almost normal to diffuse tubular atrophy and interstitial fibrosis [8], and tubulointerstitial damage has been

\section{Biomed Central}


reported to be an important risk factor on progression of IgAN [9-12]. So we took advantage of our IgAN cohort to investigate whether plasma uric acid level associated with tubular interstitial lesions, and furthermore could be considered as a maker for tubular/interstitial lesions, especially at early stage with normal eGFR.

\section{Methods}

\section{Subjects}

623 individuals (342 males and 281 females), were randomizely recruited from the IgA Nephropathy database at Renal Division of Peking University First Hospital. Among them, 258 individuals with estimated GFR $($ eGFR $)>=90 \mathrm{ml} / \mathrm{min} / 1.73 \mathrm{~m}^{2}$. Characteristics of the population were listed in Table 1 . eGFR was calculated with the equation developed from data the Chronic Kidney Disease Epidemiology Collaboration (CKD-EPI) equation [13].

The protocal for this study was approved by the Medicial Ethics Committee of Peking University and informed written consent for this study was obtained from every participant.

\section{Evaluation of renal pathological changes}

Two pathologists re-evaluated the renal biopsy slides with Oxford classification system of IgAN. Briefly, microscopic slides of all cases were reviewed independently by each of the pathologists. Histological parameters were evaluated as: 1) Mesangial hypercellularity score (If more than half the glomeruli have more than three cells in a mesangial area, this is categorized as M1, otherwise as M0; $M 0 \leq 0.5$ / M1 > 0.5); 2) Endocapillary hypercellularity (hypercellularity due to increased number of cells within glomerular capillary lumina causing narrowing of the lumina, E0 as absent/E1 as present); 3) Segmental glomerulosclerosis (any amount of the tuft involved in sclerosis, but not involving the whole tuft or the present of an adhesion, S0 means absent /S1 means present); 4) Interstitial fibrosis/ tubular atrophy (percentage of cortical area involved by the tubular atrophy or interstitial fibrosis, T0: 0-25\%/ T1: $26-50 \% / T 2:>50 \%)[14,15]$. Meanwhile, the histological changes of interstitial fibrosis/tubular atrophy were also graded by Beijing classification system of IgAN in present study (T0: 0\%/T1: < 10\%/T2: 10-24\%/ T3:25-49\%/T4: >= 50\%) [16].

\section{Statistical analyses}

Statistical Package for the Social Sciences (SPSS v13.0; Chicago, IL) was used. Baseline characteristics were reported as mean \pm SEM or median (inter-quartile range [IQR]) for continuous variables and proportions for categorical variables. Association of plasma uric acid levels and tubular atrophy/interstitial fibrosis was analyzed by univariate analysis with covariates (age, gender, BMI,
Table 1 Baseline characteristics of the IgAN corhort

\begin{tabular}{|c|c|c|}
\hline & $N=623$ & $\begin{array}{l}\mathrm{N}=258(\mathrm{eGFR}>=90 \mathrm{ml} / \\
\left.\mathrm{min} / 1.73 \mathrm{~m}^{2}\right)\end{array}$ \\
\hline Age (years) & $33.2 \pm 0.5$ & $28.8 \pm 0.6$ \\
\hline Male/Female (N) & $342 / 281$ & $120 / 138$ \\
\hline $\mathrm{BMI}\left(\mathrm{kg} / \mathrm{m}^{2}\right)$ & $24.8 \pm 0.3$ & $22.9 \pm 0.6$ \\
\hline SBP $(\mathrm{mmHg})$ & $118.7 \pm 0.7$ & $115 \pm 1.1$ \\
\hline $\mathrm{DBP}(\mathrm{mmHg})$ & $74.8 \pm 0.6$ & $72.6 \pm 1.0$ \\
\hline $\operatorname{eGFR}\left(\mathrm{ml} / \mathrm{min} / 1.73 \mathrm{~m}^{2}\right)$ & $84.2 \pm 1.4$ & $112.9 \pm 1.8$ \\
\hline $\mathrm{pCr}(\mu \mathrm{mol} / \mathrm{L})$ & $108.0 \pm 3.0$ & $72.8 \pm 0.8$ \\
\hline $\mathrm{pUA}(\mu \mathrm{mol} / \mathrm{L})$ & $374.3 \pm 4.4$ & $338.2 \pm 6.7$ \\
\hline Hyperuricemia (Y/N) (\%) & $51.5 / 48.5$ & $37.9 / 62.1$ \\
\hline TC $(\mathrm{mmol} / \mathrm{L})$ & $4.9 \pm 0.1$ & $4.7 \pm 0.1$ \\
\hline TG (mmo/L) & $1.5(1.0-2.3)$ & $1.4(0.8-2.2)$ \\
\hline $\mathrm{pNa}^{+}(\mathrm{mmol} / \mathrm{L})$ & $140.4 \pm 0.2$ & $139.8 \pm 0.2$ \\
\hline UP (g/24 h) & $1.4(0.7-1.6)$ & $1.3(0.6-2.3)$ \\
\hline \multicolumn{3}{|l|}{ Oxford score $[14,15]$} \\
\hline M0/1 (\%) & $49 / 51$ & $54 / 46$ \\
\hline E0/1 (\%) & $69 / 31$ & $69 / 31$ \\
\hline SO/1 (\%) & $53 / 47$ & $61 / 39$ \\
\hline T0/1/2 (\%) & $79 / 10 / 11$ & $95 / 3 / 2$ \\
\hline \multicolumn{3}{|l|}{ Beijing score [16] } \\
\hline Т 0/1/2/3/4 (\%) & $7 / 53 / 19 / 10 / 11$ & $13 / 68 / 14 / 3 / 2$ \\
\hline \multicolumn{3}{|l|}{ Medicine (\%) } \\
\hline Allopurinol & 0 & 0 \\
\hline Benzbromarone & 0 & 0 \\
\hline Diuretics & 10 & 0 \\
\hline Losartan & $\mathrm{N} / \mathrm{A}$ & N/A \\
\hline$A C E i+A R B$ & 42 & 42 \\
\hline
\end{tabular}

Data were presented as Mean \pm SEM or median (inter-quartile range [IQR]) for continuous variables and proportions for categorical variables. SBP: Systolic blood pressure; DBP: Diastolic blood pressure; UP: Urinary protein; pCr: Plasma creatinine; $\mathrm{pNa}^{+}$: Plasma sodium; TC: Total cholesterol; TG: Triglyceride. ACEi: Angiotensin converting enzyme inhibitor; ARB: Angiotensin receptor blocker.

proteinuria, systolic blood pressure, diastolic blood pressure and other pathological parameters) adjustment. Correlation among plasma uric acid levels, eGFR and tubulointerstitial lesions were analyzed with Spearman's correlation in the whole cohort and the subgroup with different eGFR. Logistic regression was performed to detect whether hyperuricemia was a predictor of tubulointerstitial changes. In each Model, physical and biochemical traits including age, gender, eGFR, urinary protein, systolic blood pressure, diastolic blood pressure and hyperuricemia were analyzed by single factor analysis first, and significant factors were put into multiple factor model. Chi-square was used to calculate sensitivity and specificity of hyperuricemia prediction of tubulointerstitial change. 


\section{Results}

\section{General data}

General baseline data within one week before renal biopsy were collected. Among the $623 \mathrm{IgAN}, 258$ cases presented with normal eGFR $\left(>=90 \mathrm{ml} / \mathrm{min} / 1.73 \mathrm{~m}^{2}\right)$. The pathological changes of all cases were evaluated with Oxford classification system, and tubulointerstitial changes were reevaluated with Beijing classification system as well (Table 1).

\section{Plasma uric acid levels associated with tubular atrophy and interstitial fibrosis}

We found that plasma uric acid level associated with percentage of interstitial fibrosis/tubular atrophy. Higher plasma uric acid levels indicated higher tubulointerstitial scores, either with Oxford system $(P=0.012$; Table 2$)$ or with Beijing system ( $\mathrm{P}=4.8 * 10^{-4}$; Table 2$)$.

We did the same analyses in the subgroup of 258 IgAN cases with normal baseline eGFR (eGFR > $=90 \mathrm{ml} / \mathrm{min} /$ $1.73 \mathrm{M}^{2}$, Table 2). With Beijing classification system we also found that tubulointerstitial scores associated with plasma uric acid levels in the subgroup of normal eGFR $\left(\mathrm{P}=3.4 * 10^{-5}\right.$; Table 2$)$, higher plasma uric acid associated with more severe tubulointerstitial lesions.
In Beijing scoring system, tubular atrophy/interstitial fibrosis more than $10 \%$ was identified as cut-off point of higher risk for ESRD [16]. Similarly more than 25\% of tubular atrophy/interstitial fibrosis also increased risk of GFR decline in Oxford system. So here we re-attributed all individuals into two groups, by $10 \%$ interstitial fibrosis/ tubular atrophy (Tadj_Bj0 $<10 \%$, Tadj_Bi1 $>=10 \%$ ), then by $25 \%$ interstitial fibrosis/tubular atrophy (Tadj_Ox0 $<=25 \%$, Tadj_Ox1 > 25\%) and re-analyzed the association of interstitial fibrosis/tubular atrophy with plasma uric acid level, both in the whole cohort and subgroup with normal eGFR. Again, tubulointerstitial changes divided by $25 \%$ or $10 \%$ interstitial fibrosis/tubular atrophy associated with plasma uric acid levels. Patients with more tubular atrophy/interstitial fibrosis had higher plasma uric acid level (Table 2).

\section{Hyperuricemia as a clinical marker of tubular atrophy/ interstitial fibrosis}

Since higher plasma uric acid levels associated with more tubular atrophy/interstitial fibrosis, we further analyzed whether hyperuricemia was a predictor of tubular atrophy/interstitial fibrosis in IgAN. It showed that

Table 2 Plasma uric acid levels associated with tubular atrophy/interstitial fibrosis in IgA nephropathy

\begin{tabular}{|c|c|c|c|c|c|}
\hline & The whole coh & & Subgroup & $\left(\mathrm{eGFR}>=90 \mathrm{ml} / \mathrm{min} / 1.73 \mathrm{~m}^{2}\right)$ & $\mathbf{P}$ \\
\hline & PUA ( $\mu \mathrm{mol} / \mathrm{L})$ & $\mathbf{P}$ & PUA ( $\mu \mathrm{mol} / \mathrm{L})$ & & \\
\hline Oxford score & & & & & \\
\hline TO $(\mathrm{N}=494)$ & $359.2+/-4.8$ & & T0 $(N=246)$ & $335.9+/-6.9$ & \\
\hline $\mathrm{T} 1(\mathrm{~N}=59)$ & $411.9+/-13.8$ & 0.012 & $\mathrm{~T} 1(\mathrm{~N}=8)$ & $363.4+/-35.8$ & 0.256 \\
\hline $\mathrm{T} 2(\mathrm{~N}=70)$ & $449.1+/-12.8$ & & $\mathrm{~T} 2(\mathrm{~N}=4)$ & $416.7+/-53.7$ & \\
\hline Tadj_Ox & & & & & \\
\hline Tadj_OXO & $359.2+/-4.8$ & & Tadj_OxO $(N=246)$ & $335.9+/-6.9$ & \\
\hline$(N=494)$ & & & & & \\
\hline Tadj_OX1 & $432.1+/-9.4$ & $1.5^{*} 10^{-11}$ & Tadj_OX1 $(N=12)$ & $349.8+/-2.8$ & 0.150 \\
\hline$(N=129)$ & & & & & \\
\hline Beijing score & & & & & \\
\hline T0 $(\mathrm{N}=46)$ & $340.9+/-15.5$ & & T0 $(N=34)$ & $335.9+/-18.3$ & \\
\hline $\mathrm{T} 1(\mathrm{~N}=332)$ & $351.9+/-5.8$ & & $\mathrm{~T} 1(\mathrm{~N}=175)$ & $328.5+/-8.1$ & \\
\hline $\mathrm{T} 2(\mathrm{~N}=118)$ & $387.0+/-9.7$ & $4.8^{*} 10^{-4}$ & $\mathrm{~T} 2(\mathrm{~N}=37)$ & $371.8+/-17.6$ & $3.4^{*} 10^{-5}$ \\
\hline $\mathrm{T} 3(\mathrm{~N}=57)$ & $413.7+/-13.9$ & & $\mathrm{~T} 3(\mathrm{~N}=8)$ & $363.8+/-37.8$ & \\
\hline $\mathrm{T} 4(\mathrm{~N}=70)$ & $449.1+/-12.6$ & & $\mathrm{~T} 4(\mathrm{~N}=4)$ & $416.7+/-53.7$ & \\
\hline Tadj_Bj & & & & & \\
\hline Tadj_BjO & $350.5+/-5.5$ & & Tadj_Bjo $(N=209)$ & $329.7+/-7.4$ & \\
\hline$(N=378)$ & & & & & \\
\hline Tadj_Bj1 & $411.0+/-6.8$ & 0.004 & Tadj_Bj1 $(N=49)$ & $374.2+/-15.2$ & $2.3^{*} 10^{-4}$ \\
\hline$(N=245)$ & & & & & \\
\hline
\end{tabular}

Data was presented as Mean \pm SEM. Analyses were performed with univariate analysis in the whole cohort and the subgroup. PUA: plasma uric acid. Tubular atrophy/ interstitial fibrosis was analyzed as Oxford score, Beijing score separately, and adjusted by age, gender, BMI, eGFR, proteinuria, drug therapy and other pathological items. Tadj_Ox: all individuals were re-attributed into two groups, according to $25 \%$ interstitial fibrosis/tubular atrophy (Tadj_Ox0 <= 25\%, Tadj_Ox1 $>25 \%$ ), or to $10 \%$ interstitial fibrosis/tubular atrophy (Tadj_Bj0 $<10 \%$, Tadj_Bj1 > = 10\%). 
eGFR correlated better with tubulointerstitial score than plasma uric acid levels, both in the whole group and the subgroup with eGFR less than $90 \mathrm{ml} / \mathrm{min}$. But in the subgroup with higher eGFR ( $>=90 \mathrm{ml} / \mathrm{min}$ ), only plasma uric acid level correlated with tubulointerstitial score (Table 3). In the logistic multivariate analysis model, variables assessed as potential predictors included age, gender, blood pressure, BMI, proteinuria, eGFR. A combined model of eGFR and hyperuricemia status predicted tubular atrophy/interstitial fibrosis in the whole cohort. The risk of having more than $10 \%$ tubulointerstitial lesions in patients with hyperuricemia increased 58\% compared with normal uric acid level. In subgroup with higher eGFR ( $>=90 \mathrm{ml} / \mathrm{min}$ ), only hyperuricemia predicted tubulointerstitial lesions, and the risk of having more tubulointerstitial changes increased $100 \%$ (Table 4). However in the subgroup with GFR less than $90 \mathrm{ml} / \mathrm{min}$, decrease of eGFR is the main risk factor for tubulointerstitial lesions.

Among these patients, hyperuricemia associated with more tubulointerstitial lesions with a specificity of $60.3 \%$. Specificity increased to $65 \%$ among those patients with eGFR > =90 ml/min $/ 1.73 \mathrm{~m}^{2}$ (Table 5).

\section{Discussion}

Tubulointerstitial damage has been reported to be an important risk factor for progression of IgAN [9-12].

Table 3 Correlation among tubulointerstitial score and plasma uric acid concentration in different eGFR groups

\begin{tabular}{|c|c|c|c|c|c|}
\hline & T Oxford score & Tadj_Ox & T Beijing score & Tadj_Bj & GFR \\
\hline \multicolumn{6}{|c|}{ The whole cohort $(N=623)$} \\
\hline GFR & -0.473 & -0.425 & -0.513 & -0.451 & \\
\hline p & $<0.001$ & $<0.001$ & $<0.001$ & $<0.001$ & \\
\hline PUA & 0.262 & 0.257 & 0.284 & 0.261 & -0.371 \\
\hline p & $<0.001$ & $<0.001$ & $<0.001$ & $<0.001$ & $<0.001$ \\
\hline \multicolumn{6}{|c|}{ Subgroup with eGFR $>=90 \mathrm{ml} / \mathrm{min} / 1.73 \mathrm{~m}^{2}(\mathrm{~N}=258)$} \\
\hline GFR & -0.082 & 0.031 & -0.002 & -0.031 & \\
\hline p & 0.187 & 0.625 & 0.979 & 0.618 & \\
\hline PUA & 0.102 & 0.052 & 0.133 & 0.162 & -0.160 \\
\hline p & 0.104 & 0.405 & 0.032 & 0.009 & 0.010 \\
\hline
\end{tabular}

Subgroup with eGFR $<90 \mathrm{ml} / \mathrm{min} / 1.73 \mathrm{~m}^{2}(\mathrm{~N}=365)$

\begin{tabular}{llllll} 
GFR & -0.490 & -0.503 & -0.493 & -0.378 & \\
$\mathbf{p}$ & $<0.001$ & $<0.001$ & $<0.001$ & $<0.001$ & \\
PUA & 0.234 & 0.240 & 0.243 & 0.199 & -0.374 \\
$\mathbf{p}$ & $<0.001$ & $<0.001$ & $<0.001$ & $<0.001$ & $<0.001$ \\
\hline
\end{tabular}

Analyses were performed with Spearman's correlation in the whole cohort and the subgroup with different GFR. PUA: plasma uric acid. Tubular atrophy/ interstitial fibrosis was analyzed as Oxford score, Beijing score Tadj_Ox: all individuals were re-attributed into two groups, according to $25 \%$ interstitial fibrosis/tubular atrophy (Tadj_Ox0 $<=25 \%$, Tadj_Ox1 $>25 \%$ ); Tadj_Bj: all individuals were re-attributed to $10 \%$ interstitial fibrosis/tubular atrophy (Tadj_Bj0 $<10 \%$, Tadj_Bj1 $>=10 \%$ ).
Table 4 Multivariate analysis for predictors of $10 \%$ tubular atrophy/interstitial fibrosis in IgA nephropathy

\begin{tabular}{|c|c|c|c|}
\hline Predictors & OR & 95\%C.I. & $\mathbf{P}$ \\
\hline \multicolumn{4}{|c|}{ The whole cohort $(\mathrm{N}=623)$} \\
\hline eGFR & 0.968 & $0.961-0.975$ & $<0.001$ \\
\hline HUA & 1.585 & $1.091-2.303$ & 0.016 \\
\hline \multicolumn{4}{|c|}{ Subgroup with eGFR $>=90 \mathrm{ml} / \mathrm{min} / 1.73 \mathrm{~m}^{2}(\mathrm{~N}=258)$} \\
\hline HUA & 2.097 & $1.112-3.957$ & 0.022 \\
\hline \multicolumn{4}{|c|}{ Subgroup with eGFR $<90 \mathrm{ml} / \mathrm{min} / 1.73 \mathrm{~m}^{2}(\mathrm{~N}=365)$} \\
\hline eGFR & 0.9578 & $0.944-0.969$ & $<0.001$ \\
\hline
\end{tabular}

Analyses were performed with logistic regressions in the whole cohort and the subgroup. Tubular atrophy/ interstitial fibrosis were analyzed as two groups, less than $10 \%$ interstitial fibrosis/tubular atrophy or more than $10 \%$ lesion (Tadj_Bj0 < 10\%, Tadj_Bj1 >=10\%). In each Model, physical and biochemical traits including age, gender, BMI, baseline-eGFR, baseline UP, SBP, DBP, drug therapy and hyperuricemia status were analyzed by single factor analysis first, and factors that were significant were then put into multiple factor model. Result by multiple factor analysis was presented. HUA: hyperuricemia (male $>420 \mu \mathrm{mol} / \mathrm{L}$, female $>360 \mu \mathrm{mol} / \mathrm{L}$ ); eGFR: estimated GFR.

Many IgAN patients have tubular atrophy and interstitial fibrosis even with normal eGFR. And it appeared that pathological examination was the only method to detect renal tubulointerstitial lesions. Hyperuricemia has been an interesting clinical symptom in IgAN patients and considered to be associated with prognosis of the disease $[1,17,18]$. As early as 1975 , Berger et al. has reported that $20-60 \%$ patients with gout also have mild to moderate renal dysfunction [19]. Besides influence of glomerular filtration rate on elimination of uric acid, several studies suggested that renal tubules play crucial roles in the regulation of uric acid balance in the body [20,21]. Thus we systematically evaluated the pathological changes of 623 individuals with IgAN by Oxford classification system $[14,15]$, as well as the classification for tubulointerstitial changes in Beijing system [16] and found that tubular atrophy/interstitial fibrosis associated with plasma uric acid levels. The higher plasma uric acid levels indicated higher tubulointerstitial scores. And we also found similar association in the subgroup with normal eGFR. Finally, we identified that hyperuricemia could be a marker to predict tubular atrophy/interstitial fibrosis in IgAN, especially in those with normal eGFR.

Table 5 Specificity and sensitivity for predicting tubular atrophy/interstitial fibrosis by hyperuricemia in IgA Nephropathy

\begin{tabular}{cccc}
\hline Sensitivity & Specificity & $\mathrm{P}$ (Chi-square) & $\mathrm{P}$ (Exact) \\
\hline
\end{tabular}

The whole cohort

HUA $62.0 \% \quad 60.3 \% \quad 4.9^{*} 10^{-8} \quad 5.5^{*} 10^{-8}$

The subgroup with normal eGFR ( $>=90 \mathrm{ml} / \mathrm{min} / 1.73 \mathrm{~m}^{2}$ )

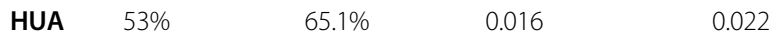

HUA: hyperuricemia. 
In our study, we took advantage of the new pathological classification system, Oxford system $[14,15]$ as well as Beijing system [16] and did analysis in whole cohort of 623 IgAN patients, then in subgroup with eGFR $>=90 \mathrm{ml} / \mathrm{min} / 1.73 \mathrm{~m}^{2}$ and subgroup with eGFR $<90 \mathrm{ml} /$ min. Our result showed that eGFR correlated with tubulointerstitial score better than plasma uric acid levels in the whole cohort and in the subgroup with eGFR less than $90 \mathrm{ml} / \mathrm{min}$. Lower eGFR correlated with severe tubulointerstitial lesions. However in the subgroup with eGFR $>=90 \mathrm{ml} / \mathrm{min}$, eGFR did not correlate with tubulointerstitial score anymore, only uric acid levels presented correlation with the scores. Previously published reports also found that plasma uric acid correlated with pathological changes in 202 cases of IgAN, in which the best correlation coefficients were 0.42 for interstitial fibrosis and 0.39 for tubular atrophy [17]. Although our study did not identified such high correlation coefficients for plasma uric acid and tubulointerstitial lesions, we found that plasma uric acid but not eGFR was an factor associated with tubulointerstitial changes in patients with obviously normal eGFR. However when eGFR decreased, eGFR itself may be correlating with tubulointerstitial changes.

Since tubular atrophy/interstitial fibrosis more than $10 \%$ was identified as cut-off point of higher risk for ESRD in Beijing scoring system [16] and more than 25\% tubular atrophy/interstitial fibrosis increased risk of GFR decline in Oxford system, we collapsed individuals into two groups by cut-off point at $10 \%$ for Beijing scoring system, then by $25 \%$ interstitial fibrosis/tubular atrophy for Oxford scoring system. We set up two models of multivariate logistic regression, in which dependent variable was tubulointerstitial lesion by $10 \%$ cut off in model 1 and tubulointerstitial lesion by $25 \%$ cut off in model 2 . For model 1, the risk of having more than $10 \%$ tubulointerstitial lesions in IgAN patients with hyperuricemia increased compared with normouricemia in whole cohort as well as in subgroup with normal eGFR. For model 2, none of the clinical signs predicted tubulointerstitial changes. These may be explained by the time of renal biopsy. Most patients accepted renal biopsy were attributed to less than $25 \%$ tubulointerstital lesions group, especially those with normal eGFR.

Our study showed that hyperuricemia has specificity of $60-64 \%$ to be associated with tubulointerstitial lesions in IgAN. Although it is much less than accepted levels of specificity $80 \%$ to consider hyperuricemia a predictor for tubulointerstitial lesions, the specificity still indicated the close association of hyperuricemia with tubulointerstitial score.

In summary, this observation study at an IgAN cohort revealed that interstitial fibrosis/tubular atrophy was associated with plasma uric acid levels in IgAN and plasma uric acid level was a hopeful clinical marker indicating tubulointerstitial lesions especially in patients with normal eGFR.

\section{Conclusions}

Hyepruricemia appeared to be a common symptom in IgA nephropathy. We took advantage of our IgAN cohort and found that plasma uric acid level indicates tubulointerstitial lesions in IgAN and hyperuricemia may be considered as a marker for tubulointerstitial lesions.

\section{Competing interest}

The authors declare that they have no competing interest.

\section{Authors' contributions}

CYQ conceived of the study, and participated in its design and coordination and helped to draft the manuscript. ZJJ collected the clinical data and drafted the manuscript. LY participated in the collection of clinical data. SUF and WSX re-evaluated the renal biopsy slides with Oxford classification system and Beijing classification system of IgA nephropathy. LXY helped to perform the statistical analysis. ZH participated in the design of the study. All authors read and approved the final manuscript.

\section{Acknowledgements}

We appreciate the assistance of A Grant of the Medical Development of the Capital (2009-2019).

\section{Author details}

'Renal Division, Department of Medicine, Peking University First Hospital, Beijing 100034, China. ${ }^{2}$ Institute of Nephrology, Peking University, Beijing 100034, China. ${ }^{3}$ Key Laboratory of Renal Disease, Ministry of Health of China, Beijing 100034, China. ${ }^{4}$ Key Lab of Chronic Kidney Disease Prevention and Treatment, Ministry of Education, Beijing 100034, China. ${ }^{5}$ Department of Statistics, Peking University First Hospital, Beijing 100034, China. '́Laboratory of Electron Microscopy, Peking University First Hospital, Beijing 100034, China.

Received: 28 February 2013 Accepted: 3 January 2014

Published: 14 January 2014

\section{References}

1. Syrjanen J, Mustonen J, Pasternack A: Hypertriglyceridaemia and hyperuricaemia are risk factors for progression of IgA nephropathy. Nephrol Dial Transplant 2000, 15:34-42.

2. Iseki K, Ikemiya Y, Inoue T, Iseki C, Kinjo K, Takishita S: Significance of hyperuricemia as a risk factor for developing ESRD in a screened cohort. Am J Kidney Dis 2004, 44:642-650.

3. Chonchol M, Shlipak MG, Katz R, Sarnak MJ, Newman AB, Siscovick DS, Kestenbaum B, Carney JK, Fried LF: Relationship of uric acid with progression of kidney disease. Am J Kidney Dis 2007, 50:239-247.

4. Chang HY, Tung CW, Lee PH, Lei CC, Hsu YC, Chang HH, Yang HF, Lu LC, Jong MC, Chen CY, Fang KY, Chao YS, Shih YH, Lin CL: Hyperuricemia as an independent risk factor of chronic kidney disease in middle-aged and elderly population. Am J Med Sci 2010, 339:509-515.

5. Aringer $M$, Graessler J: Understanding deficient elimination of uric acid. Lancet 2008, 372:1929-1930.

6. Kutzing MK, Firestein BL: Altered uric acid levels and disease states. J Pharmacol Exp Ther 2008, 324:1-7.

7. Mount DB, Kwon CY, Zandi-Nejad K: Renal urate transport. Rheum Dis Clin North Am 2006, 32:313-331.

8. Barratt J, Feehally J: IgA Nephropathy. J Am Soc Nephrol 2005, 16:2088-2097.

9. Walsh M, Sar A, Lee D, Yilmaz S, Benediktsson H, Manns B, Hemmelgarn B: Histopathologic features aid in prediciton risk for progression of $\lg A$ nephropathy. Clin J Am Soc Nephrol 2010, 5:425-430.

10. LV J, Zhang H, Zhou Y, Li G, Zou W, Wang H: Natural history of immunoglobulin A nephropathy and predictive factors of prognosis: a 
long-term follow up of 204 cases in China. Nephrology (Carlton) 2008, 13:242-246

11. Reich HN, Troyanov S, Scholey JW, Cattran DC, Toronto Glomerulonephritis Registry: Remission of proteinuria improves prognosis in IgA nephropathy. $J$ Am Soc Nephrol 2007, 18:3177-3183.

12. D'Amico G: Natural history of idiopathic IgA nephropathy: role of clinical and histological prognostic factors. Am J Kidney Dis 2000, 36:227-237.

13. Levey AS, Stevens LA, Schmid CH, Zhang YL, Castro AF 3rd, Feldman HI, Kusek JW, Eggers P, Van Lente F, Greene T, Coresh J, CKD-EPI (Chronic Kidney Disease Epidemiology Collaboration): A new equation to estimate glomerular filtration rate. Ann Intern Med 2009, 150:604-612.

14. Working Group of the International IgA Nephropathy Network and the Renal Pathology Society, Roberts IS, Cook HT, Troyanov S, Alpers CE, Amore A, Barratt J, Berthoux F, Bonsib S, Bruijn JA, Cattran DC, Coppo R, D'Agati V, D'Amico G, Emancipator S, Emma F, Feehally J, Ferrario F, Fervenza FC Florquin S, Fogo A, Geddes CC, Groene HJ, Haas M, Herzenberg AM, Hill PA, Hogg RJ, Hsu SI, Jennette JC, Joh K, et al: The Oxford classification of IgA nephropathy: pathology definitions, correlations, and reproducibility. Kidney Int 2009, 76:546-556.

15. Working Group of the International IgA Nephropathy Network and the Renal Pathology Society, Cattran DC, Coppo R, Cook HT, Feehally J, Roberts IS, Troyanov S, Alpers CE, Amore A, Barratt J, Berthoux F, Bonsib S, Bruijn JA, D'Agati V, D'Amico G, Emancipator S, Emma F, Ferrario F, Fervenza FC, Florquin S, Fogo A, Geddes CC, Groene HJ, Haas M, Herzenberg AM, Hill PA, Hogg RJ, Hsu SI, Jennette JC, Joh K, et al: The Oxford classification of IgA nephropathy: rationale, clinicopathological correlations, and classification. Kidney Int 2009, 76:534-545.

16. Jiang L, Liu G, Lv J, Huang C, Chen B, Wang S, Zou W, Zhang H, Wang H: Concise semiquantitative histological scoring system for immunoglobulin A nephropathy. Nephrology (Carlton) 2009, 14:597-605.

17. Myllymäki J, Honkanen T, Syräanen J, Helin H, Rantala I, Pasternack A, Mustonen J: Uric acid correlates with the severity of histopathological parameters in IgA nephropathy. Nephrol Dial Transplant 2005, 20:89-95.

18. Ohno I, Hosoya T, Gomi H, Ichida K, Okabe H, Hikita M: Serum uric acid and renal prognosis in patients with IgA nephropathy. Nephron 2001, 87:333-339.

19. Berger L, Yu TF: Renal function in gout. IV. An analysis of 524 gouty subjects including long-term follow-up studies. Am J Med 1975, 59:605-613.

20. Vitart V, Rudan I, Hayward C, Gray NK, Floyd J, Palmer CN, Knott SA, Kolcic I, Polasek O, Graessler J, Wilson JF, Marinaki A, Riches PL, Shu X, Janicijevic B, Smolej-Narancic N, Gorgoni B, Morgan J, Campbell S, Biloglav Z, Barac-Lauc L, Pericic M, Klaric IM, Zgaga L, Skaric-Juric T, Wild SH, Richardson WA, Hohenstein P, Kimber CH, Tenesa A, et al: SLC2A9 is a newly identified urate transporter influencing serum urate concentration, urate excretion and gout. Nat Genet 2008, 40:437-442.

21. Enomoto A, Kimura H, Chairoungdua A, Shigeta Y, Jutabha P, Cha SH, Hosoyamada M, Takeda M, Sekine T, Igarashi T, Matsuo H, Kikuchi Y, Oda T, Ichida K, Hosoya T, Shimokata K, Niwa T, Kanai Y, Endou H: Molecular identification of a renal urate anion exchanger that regulates blood urate levels. Nature 2002, 417:447-452.

doi:10.1186/1471-2369-15-11

Cite this article as: Zhou et al.: Plasma uric acid level indicates tubular interstitial leisions at early stage of IgA nephropathy. BMC Nephrology 2014 15:11.

\section{Submit your next manuscript to BioMed Central and take full advantage of:}

- Convenient online submission

- Thorough peer review

- No space constraints or color figure charges

- Immediate publication on acceptance

- Inclusion in PubMed, CAS, Scopus and Google Scholar

- Research which is freely available for redistribution 